\title{
ANALISIS PENGARUH FINANCIAL LITERACY, FUTURE ORIENTATION, USIA DAN GENDER TERHADAP PERENCANAAN DANA PENSIUN PNS DI KOTA SURABAYA
}

\author{
Kurnia Dwi Sandra \\ Universitas Negeri Surabaya \\ kurniasandra16080574089@mhs.unesa.ac.id \\ Achmad Kautsar \\ Universitas Negeri Surabaya \\ achmadkautsar@unesa.ac.id
}

Abstract

Retirement planning is an important thing that should be a concern and implemented by every working people to achieve their happiness in retirement years, especially in countries like Indonesia, which experience a significant increase in the number of elderly each year. Focus on civil servants who are guaranteed pension funds from the government, each year, the number of workers who enter retirement age. This research aims to determine the effect of financial literacy, future orientation, age, and gender on retirement planning. The research sample is 110 respondents who are civil servants in Surabaya-collecting data by online questionnaires. The data analysis technique uses multiple linear regression by SPSS. This research results in financial literacy and future orientation positively affecting retirement planning. In contrast, the variables age and gender did not affect retirement planning.

Keywords: retirement planning; financial literacy; future orientation.

\section{PENDAHULUAN}

Perencanaan dana pensiun merupakan proses menentukan tujuan pengelolaan penghasilan saat masa pensiun, yang mencakup identifikasi sumber pendapatan, memperkirakan kebutuhan dan biaya, serta pengimplementasian program tabungan serta aset (Sufian, 2016). Pada tahun 2016, berdasarkan data dari CIA World Factbook Indonesia termasuk negara dengan jumlah penduduk terbesar keempat di dunia. Jumlah penduduk di Indonesia pada tahun 2015 sebanyak 255,641 juta jiwa, tahun 2020 sebanyak 271,066 juta jiwa, dan terus mengalami peningkatan hingga pada tahun 2025 sebanyak 284,829 juta jiwa (BPS, 2014).

Pertumbuhan jumlah penduduk yang terus meningkat juga diikuti dengan peningkatan jumlah penduduk lansia. Pada tahun 2010 jumlah penduduk lansia sebesar 7,6\% dari total jumlah penduduk, tahun 2015 sebesar 8,5\%, tahun 2020 sebesar 10,8\%, dan terus mengalami peningkatan hingga diperkirakan pada tahun 2035 dapat mencapai 15,8\% (BPS, 2017).

Peningkatan populasi penduduk lansia yang begitu pesat seharusnya diimbangi dengan melakukan upaya perencanaan kesejahteraan keuangan di masa tuanya yang dapat dilakukan dengan melakukan antisipasi dan perencanaan pada dana pensiunnya (Wardani \& Silvy, 2018). Namun, CNN Indonesia (2018) menyebutkan bahwa angka wirausahawan hanya sebesar 3,1\% dari jumlah penduduk usia produktif di Indonesia. Hal ini menunjukkan sebagian besar masyarakat hanya mengandalkan pendapatan dari pekerjaan yang sedang dimiliki dan mengesampingkan minat berwirausaha yang seharusnya dapat menjadi sumber pendapatan jangka panjang terutama setelah memasuki masa pensiun.

Masa pensiun merupakan masa dimana seseorang sudah mulai berhenti untuk bekerja, dikarenakan faktor usia ataupun fisik yang sudah tidak produktif (Kusumawanti, 2018). Setiap orang pasti menginginkan kehidupan yang sejahtera di masa pensiunnya, karena sudah tidak mampu untuk bekerja namun kebutuhan hidup terus berjalan. Oleh karena itu, salah satu hal yang dapat dilakukan adalah dengan melakukan perencanaan terhadap dana pensiun (Mustikarahmawati, 2018). 
Kurnia Dwi Sandra \& Achmad Kautsar. Analisis Pengaruh Financial Literacy, Future Orientation, Usia dan Gender terhadap Perencanaan Dana Pensiun PNS di kota Surabaya

Dana pensiun merupakan dana yang dialokasikan untuk diinvestasikan guna mempersiapkan kepentingan di masa tua. PT. Taspen merupakan Badan Usaha Milik Negara yang bergerak dibidang asuransi tabungan hari tua dan dana pensiun Pegawai Negeri Sipil. Salah satu program sejahteraan PNS yang dikelola oleh PT.Taspen adalah Program Pensiun, yaitu penghasilan yang diterima oleh penerima pensiun setiap bulan berdasarkan peraturan perundang-undangan yang berlaku (PT.Taspen, 2018).

Jumlah PNS terus mengalami kenaikan setiap tahunnya, berdasarkan data dari BKN (2019) jumlah CPNS meningkat dari tahun 2018 ke tahun 2019 sebesar 12\%. Jumlah keseluruhan PNS per 31 Desember 2018 adalah sebesar 4.185.503 jiwa yang tersebar di berbagi provinsi seluruh Indonesia. Berdasarkan data dari BKN beberapa provinsi dengan jumlah PNS tertinggi adalah Jawa Timur dengan total 364.493 PNS, Jawa Tengah dengan jumlah 332.859 PNS, Jawa Barat dengan jumlah 311.866 PNS dan Aceh dengan jumlah 133.814. Sehingga diketahui provinsi dengan jumlah persebaran PNS tertinggi berada pada provinsi Jawa Timur, dan berpusat di kota Surabaya dengan jumlah 14.220 PNS (BKN, 2019).

Jumlah PNS yang memasuki Batas Usia Pensiun atau BUP terus mengalami kenaikan setiap tahun. Berdasarkan data dari Menpan (2016), jumlah PNS yang memasuki BUP pada tahun 2020 mencapai 184.542 orang. Hal ini diperkuat oleh data yang dirilis oleh BKN di mana jumlah persentase PNS kelompok umur 41-60 tahun sebesar 69\%, sedangkan kelompok umur 18-40 tahun hanya 31\%.

Variabel pertama yang diteliti dalam penelitian ini adalah financial literacy. Menurut Chinen \& Endo (2012), financial literacy atau literasi keuangan merupakan kemampuan yang dimiliki oleh seseorang dalam merencanakan dan menentukan keputusan secara efektif terkait keuangan pribadi. Pada penelitian Sufian (2016) dan Putri (2013), ditemukan hasil financial literacy signifikan positif terhadap perencanaan dana pensiun. Sedangkan pada penelitian Shafee (2018) ditemukan bahwa tidak ada pengaruh yang signifikan antara financial literacy terhadap perencanaan dana pensiun.

Variabel kedua yang akan diteliti adalah future orientation. Future orientation adalah pandangan seseorang mengenai tujuan yang jelas tentang harapan di masa depan agar mampu menentukan tujuan dan menyelesaikan masalah-masalah yang mungkin timbul di masa depan (Moorthy \& Kai, 2012). Pada penelitian Kimiyagahlam et. al. (2019) dan Sugihartatik (2019), future orientation signifikan positif terhadap perencanaan dana pensiun.

Variabel ketiga adalah usia. Sufian (2016) menyatakan masyarakat dengan usia muda cenderung memiliki pemikiran bahwa mereka terlalu muda dan belum saatnya untuk berpikir tentang pensiun, sedangkan masyarakat dengan usia yang lebih tua berpikir tidak dapat menabung dengan maksimal untuk kepentingan perencanaan pensiun karena adanya kepentingan untuk memenuhi kebutuhan hidup keluarga ataupun kepentingan yang lain. Pada penelitian Sufian (2016), usia berpengaruhi positif terhadap perencanaan dana pensiun.

Variabel keempat adalah gender. Grace et. al. (2010) menyatakan laki-laki cenderung mengadopsi pilihan perspektif individu, dimana diasumsikan bahwa pensiun menjadi tahap lain dalam kehidupan yang akan menyediakan gaya hidup kondusif dengan standar hidup mereka saat ini. Sedangkan perempuan mengadopsi sangat banyak perspektif tentang kehidupan, yang tidak membuat asumsi atau prediksi tentang tahap kehidupan di masa depan. Pada penelitian Sufian (2016), gender signifikan positif terhadap perencanaan dana pensiun. Penelitian ini bertujuan untuk mengetahui pengaruh dari financial literacy, future orientation, usia, dan gender terhadap perencanaan pensiun pada PNS di kota Surabaya.

\section{KAJIAN PUSTAKA DAN PENGEMBANGAN HIPOTESIS}

\section{Theory of Planned Behavior}

Theory of Planned Behavior (Teori Tindakan yang Beralasan) pertama kali dikemukakan oleh Ajzen (1991). Teori ini berasumsi bahwa seseorang berperilaku sesuai dengan niat sadar mereka, yang 
didasarkan pada kalkulasi rasional tentang efek potensial dari perilaku yang mereka lakukan, serta bagaimana orang lain akan memandang perilaku yang dilakukan. Teori ini menyediakan suatu kerangka untuk mempelajari sikap terhadap perilaku. Sikap individu terhadap keperilakuan meliputi kepercayaan terhadap suatu perilaku, evaluasi terhadap hasil perilaku, norma subyektif, kepercayaan normatif dan motivasi untuk patuh (Kimiyagahlam et. al., 2019).

Theory of Planned Behavior didasarkan pada asumsi bahwa manusia adalah makhluk rasional dan menggunakan berbagai informasi secara sistematis (Ajzen, 1991). Dalam penelitian ini Theory of Planned behavior digunakan untuk menjelaskan variabel financial literacy dan gender.

\section{Future Time Perspective Theory}

Future Time Perspective Theory menyatakan bahwa aspek fundamental dari struktur psikologis adalah perspektif waktu yang membagi pengalaman manusia di masa lalu dan masa depan (Mischel et. al., 1989). Konsep dari Future Time Perspective Theory adalah bagaimana efek waktu pada tindakan seseorang, yaitu bagaimana waktu dapat berpengaruh pada perubahan perilaku seseorang dalam menentukan sikap, tindakan dan keputusan. Teori ini juga menjelaskan bahwa seseorang memiliki kemampuan untuk menentukan keputusan berdasarkan pertimbangan hasil jangka panjang di masa depan (Kimiyagahlam et. al., 2019).

Coudin \& Lima (2011) menyatakan bahwa Future Time Perspective Theory merupakan pandangan individu memiliki pengaruh yang kuat pada perilaku individu dalam menentukan keputusan (Kimiyagahlam et. al., 2019). Dalam penelitian ini Future Time Perspective Theory digunakan untuk menjelaskan variabel future orientation.

\section{Theory of Life Cycle Hypothesis}

Theory of Life Cycle Hypothesis pertama kali dikenalkan oleh Ando et. al. (1963) menyatakan bahwa faktor sosial ekonomi seseorang dapat memengaruhi pola konsumsi orang tersebut yang sangat tergantung pada perjalanan umurnya. Model siklus ini membagi tiga pola konsumsi berdasarkan umur seseorang, yang pertama adalah periode belum produktif (usia 0 tahun sampai dengan usia kerja), pada tahap ini seseorang melakukan pola konsumsi yang disebut dissaving. Kedua, periode produktif (usia kerja sampai dengan menjelang usia tua), pada tahap ini seseorang melakukan pola konsumsi yang disebut saving. Ketiga adalah periode tidak produktif lagi, pada tahap ini seseorang kembali ke pola konsumsi dissaving karena kondisi mereka yang sudah tidak mampu untuk memenuhi kebutuhan diri sendiri dan kembali bergantung kepada orang lain (Kim et. al., 2014).

Dalam Theory of Life Cycle Hypothesis diasumsikan bahwa individu harus memiliki perencanaan untuk dapat memenuhi kegiatan konsumsi sehari-hari selama sisa hidup meskipun sedang mengalami fluktuasi pendapatan. Selain itu, tingkat konsumsi dan besarnya tabungan dapat mencerminkan tahap individu dalam siklus hidup yang biasanya ditunjukkan oleh usia (Kim et. al., 2014). Theory of Life Cycle Hypothesis dalam penelitian ini digunakan untuk menjelaskan variabel usia.

\section{Perencanaan Dana Pensiun}

Menurut Moorthy \& Kai (2012), perencanaan dana pensiun adalah suatu tindakan yang dilakukan oleh individu untuk mencapai tujuan hidup di masa depan dengan cara mempersiapkan dan menyisihkan sebagian uang yang dimiliki. Seseorang yang tidak mempersiapkan rencana pensiun sejak awal, mereka mungkin tidak dapat mencapai tujuan pensiun yang mereka harapkan, serta mereka akan tetap membutuhkan pekerjaan meski sudah memasuki masa pensiun agar tetap memperoleh penghasilan (Asokumar, 2018).

Perencanaan dana pensiun dihitung menggunakan skala Likert. Untuk mengukur perencanaan dana pensiun seseorang dapat dilakukan dengan menggunakan tiga indikator menurut Moorthy \& Kai (2012), yaitu: (1) kesiapan keuangan dana pension, (2) standar hidup untuk dana pension, dan (3) pengeluaran saat pensiun. 
Kurnia Dwi Sandra \& Achmad Kautsar. Analisis Pengaruh Financial Literacy, Future Orientation, Usia dan Gender terhadap Perencanaan Dana Pensiun PNS di kota Surabaya

\section{Financial Literacy}

Financial literacy merupakan pengetahuan seseorang tentang keuangan dasar, simpanan, pinjaman dan juga asuransi, serta keterampilan dan kemampuan dalam berinvestasi untuk mendapat keuntungan darinya (Putri, 2018). Seseorang yang memiliki tingkat financial literacy yang tinggi dapat membuat keputusan keuangan secara bijak, serta mampu mengelola pemasukan dan pengeluaran dengan baik, dan juga memiliki inisiatif untuk menyisihkan sebagian dana untuk mempersiapkan masa depan (Putri, 2018).

Financial literacy dihitung menggunakan skala Guttman. Menurut penelitian Chen \& P.Volpe (1998) ada beberapa indikator yang dapat digunakan untuk mengukur financial literacy, yaitu : (1) Pengetahuan keuangan umum, (2) Saving, (3) Kredit, (4) Asuransi, dan (5) Investasi

\section{Future Orientation}

Menurut Moorthy \& Kai (2012), future orientation adalah pandangan seseorang mengenai tujuan yang jelas tentang harapan di masa depan agar mampu menentukan tujuan dan menyelesaikan masalah-masalah yang mungkin timbul di masa depan. Future orientation menunjukkan tingkat keseriusan seseorang dalam menentukan keputusan untuk masa depan, seperti pendidikan, pekerjaan, keluarga dan persiapan masa pensiun. Tingkat future orientation yang tinggi akan mendorong seseorang untuk berusaha mendapatkan atau mewujudkan sesuatu. Future orientation diukur menggunakan skala Likert dan mengacu pada penelitian yang dilakukan oleh Rahman (2018), dengan indikator sebagai berikut. (1) Keinginan tetap memiliki pekerjaan. (2) Cara pandang terhadap masa depan. (3) Keinginan memperoleh pensiun sejahtera. (4) Keinginan memperoleh informasi terkait pension.

\section{Usia}

Menurut Kumar et. al. (2019), seseorang dengan usia yang relatif muda menganggap pensiun merupakan hal yang jauh untuk dipikirkan dan direncanakan. Namun, untuk seseorang yang mendekati masa pensiun, mereka lebih aktif dalam kegiatan perencanaan pensiun. Meski demikian, pada dasarnya semakin bertambahnya usia manusia maka mereka akan semakin menginginkan kesejahteraan dalam hidupnya. Usia diukur menggunakan skala nominal dengan skor: (0) 25-45 tahun dan (1) 46-65 tahun. Hal ini mengacu pada Moorthy \& Kai (2012) bahwa seseorang yang berusia lebih dari 45 tahun memiliki kepedulian lebih terhadap perencanaan dana pensiunnya.

\section{Gender}

Menurut Grace et. al. (2010), laki-laki cenderung mengadopsi pilihan perspektif individu, dimana diasumsikan bahwa pensiun akan menjadi tahap lain dalam kehidupan yang akan menyediakan gaya hidup kondusif dengan standar hidup mereka saat ini. Sedangkan, perempuan mengadopsi sangat banyak perspektif kehidupan yang tidak membuat asumsi atau prediksi tentang tahap kehidupan di masa depan. Beberapa penelitian menyatakan bahwa laki-laki lebih baik dalam melakukan perencanaan pensiunnya, dikarenakan laki-laki adalah seorang kepala keluarga yang harus tetap bertanggung jawab terhadap semua kebutuhan dan biaya hidup keluarga meski telah memasuki masa pensiun. Skala yang digunakan untuk mengukur variabel gender adalah skala nominal dengan skor (1) laki-laki dan (0) perempuan.

\section{Hubungan antar Variabel}

Menurut Sufian (2016), financial literacy berpengaruh positif terhadap perencanaan dana pensiun. Hubungan ini menunjukkan semakin tinggi tingkat financial literacy yang dimiliki seseorang, maka seseorang itu memiliki tingkat kepercayaan diri yang tinggi pula dalam melakukan pengambilan keputusan keuangan. Hal ini didukung oleh Putri (2013) bahwa seseorang yang memiliki tingkat financial literacy yang tinggi dirasa memiliki pengetahuan yang baik pula mengenai keuangan dasar, sehingga dapat mengambil keputusan keuangan dengan bijak.

H1: Financial literacy berpengaruh terhadap perencanaan dana pensiun pada PNS di kota Surabaya. 
Future orientation berpengaruh signifikan positif terhadap perencanaan dana pensiun berdasarkan penelitian yang dilakukan oleh (Sugihartatik, 2019). Hal ini didukung oleh riset yang telah dilakukan oleh Kimiyagahlam et. al. (2019), future orientation memiliki pengaruh signifikan terhadap perencanaan dana pensiun. Seseorang dengan perspektif masa depan cenderung lebih mampu dalam menentukan tujuan dan memahami berbagai akibat dalam mengembangkan rencana untuk pensiun mereka.

H2: Future orientation berpengaruh terhadap perencanaan dana pensiun pada PNS di kota Surabaya.

Penelitian yang telah dilakukan oleh Moorthy \& Kai (2012), menunjukkan usia berpengaruh signifikan terhadap perencanaan dana pensiun. Perencanaan dana pensiun seharusnya dimulai dari dini agar dapat memberikan manfaat lebih baik untuk merencanakan tujuan dan impian di masa depan. Hal ini didukung oleh penelitian yang dilakukan oleh Sufian (2016) yang menemukan bahwa usia berpengaruh signifikan terhadap perencanaan dana pensiun. Dimana masyarakat dengan usia muda cenderung menunda atau belum memikirkan terkait perencanaan pensiun, sedangkan masyarakat dengan usia tua cenderung kesulitan untuk menyisihkan dana guna kepentingan masa pensiun dikarenakan memiliki tanggung jawab terhadap kebutuhan keluarga.

H3: Usia berpengaruh terhadap perencanaan dana pensiun pada PNS di kota Surabaya.

Penelitian yang dilakukan oleh Sufian (2016) membuktikan gender berpengaruh signifikan terhadap perencanaan dana pensiun. Gender berpengaruh terhadap cara pikir seseorang dalam pengambilan keputusan maupun perencanaan. Laki-laki cenderung lebih baik dalam perencanaan dana pensiunnya dibandingkan dengan perempuan. Karena laki-laki tetap harus bertanggung jawab dalam memenuhi kebutuhan dan biaya hidup keluarga nya meski telah memasuki masa pensiun.

H4: Gender berpengaruh terhadap perencanaan dana pensiun pada PNS di kota Surabaya.

\section{METODE PENELITIAN}

Jenis penelitian yang digunakan adalah penelitian kausalitas. Data yang digunakan adalah data primer yang didapat dengan menyebarkan kuesioner secara online. Variabel bebas yang digunakan dalam riset ini adalah financial literacy, future orientation, usia dan gender. Sedangkan variabel terikat pada riset ini adalah perencanaan dana pensiun. Populasi dalam penelitian ini adalah PNS yang bekerja maupun berdomisili di kota Surabaya. Jumlah sampel pada penelitian ini adalah sebanyak 110 responden, yaitu PNS dengan rentang usia 25-45 tahun dan 46-65 tahun yang diambil menggunakan teknik quota sampling dari berbagai wilayah di kota Surabaya, dengan rincian wilayah Surabaya pusat, Surabaya utara, Surabaya selatan, Surabaya timur dan Surabaya barat.

Pada pengambilan sampel penelitian, diambil 30 sampel terlebih dahulu untuk diuji validitas dan reliabilitasnya terhadap instrumen penelitian yang digunakan. Setelah data dinyatakan lolos uji, maka selanjutnya dilakukan penyebaran 110 kuesioner dan diuji kembali validitas dan reliabilitasnya guna dapat lolos uji asumsi klasik dan memenuhi model regresi linier berganda. Data yang telah terkumpul dianalisis dengan regresi linier berganda menggunakan uji asumsi klasik yang terdiri dari uji normalitas, uji multikolonieritas, dan uji heteroskedastisitas. Kemudian, data tersebut diuji menggunakan uji hipotesis dengan menggunakan uji hipotesis $\mathrm{F}$, uji statistik $\mathrm{t}$, dan yang terakhir adalah koefisien determinasi.

\section{HASIL DAN PEMBAHASAN}

\section{Uji Validitas}

Uji validitas skala Guttman pada variabel financial literacy menggunakan perhitungan Koefisien Reprodusibilitas yang menghasilkan nilai 0,925 > 0,90 dan Koefisien Skalabilitas menunjukkan hasil 
Kurnia Dwi Sandra \& Achmad Kautsar. Analisis Pengaruh Financial Literacy, Future Orientation, Usia dan Gender terhadap Perencanaan Dana Pensiun PNS di kota Surabaya

$0,851>0,60$. Nilai koefisien tersebut melebihi dari kriteria yang ditentukan. Sehingga variabel tersebut dapat dinyatakan valid. Hasil uji validitas untuk skala likert variabel future orientation dan perencanaan dana pensiun diuji menggunakan aplikasi SPSS. Hasil uji validitas variabel untuk semua item menghasilkan $r$ hitung $>r$ tabel. Nilai $r$ tabel untuk 30 responden adalah sebesar 0,3610 dan $r$ tabel untuk 110 responden adalah sebesar 0,1874. Sehingga jawaban responden dan item pernyataan dinyatakan valid dan dapat digunakan sebagai alat ukur dalam penelitian ini.

\section{Uji Reliabilitas}

Hasil uji reliabilitas untuk skala Guttman dilakukan dengan menggunakan metode KR-20 untuk variabel financial literacy memiliki nilai 0,416 sehingga berdasarkan koefisien reliabilitas guillford menunjukkan bahwa jawaban atau data yang diberikan oleh responden memiliki tingkat reliabilitas sedang. Dari hasil pengukuran menunjukkan bahwa nilai telah memenuhi syarat. Hasil uji reliabilitas untuk skala likert pada variabel future orientation dan perencanaan dana pensiun menggunakan nilai Cronbach's Alpha sebesar > 0,70 sesuai dengan (Ghozali, 2016). Variabel future orientation memiliki nilai Cronbach's alpha sebesar 0,749 dan variabel perencanaan dana pensiun memiliki nilai Cronbach's alpha sebesar 0,733. Sehingga jawaban atau data yang diberikan oleh responden telah memenuhi kriteria dan dapat dikatakan reliabel.

\section{Uji Normalitas}

Uji normalitas menggunakan analisis grafik dan uji statistik. Analisis grafik dilakukan menggunakan grafik normal probability plot yang menghasilkan data menyebar disekitar garis diagonal dan mengikuti arah garis diagonal atau grafik histogramnya. Uji statistik dilakukan menggunakan uji Kolmogrov-Sminorv (K-S), yang menghasilkan nilai uji sebesar 0,054 dengan siginifikansi sebesar 0,886 yang lebih besar dari 0,05 yang menunjukkan data residual berdistribusi normal.

\section{Uji Multikolonieritas}

Hasil uji multikolonieritas menggunakan besaran nilai VIF. Hasil dalam penelitian ini menunjukkan bahwa nilai VIF dan nilai tolerance keseluruhan variabel independen dalam penelitian ini memiliki nilai $<10$ dan $>0$, 1 . Maka, disimpulkan model regresi dalam penelitian ini tidak mengalami gejala multikolonieritas.

\section{Uji Heteroskedastisitas}

Hasil uji Heteroskedastisitas menggunakan pengamatan grafik scatterplot dan uji spearman. Pada grafik scatterplot menunjukkan penyebaran titik-titik secara acak baik di atas maupun di bawah angka 0 pada sumbu Y. Uji spearman dilakukan dengan melihat nilai signifikansi dari keseluruhan variabel independen yang menghasilkan nilai $>0,05$. Sehingga dapat disimpulkan tidak terjadi heteroskedastisitas pada penelitian ini.

\section{Regresi Linier Berganda}

Hasil regresi linier berganda ditunjukkan oleh tabel 1, dengan persamaan regresi (1). Persamaan regresi memberikan hasil konstanta sebesar -3,945 yang dapat diartikan perencanaan dana pensiun yang dilakukan oleh PNS sebesar -3,945 apabila keseluruhan variabel konstan. Financial literacy memiliki koefisien regresi sebesar 1,702 yang dapat diartikan setiap financial literacy meningkat 1000 kali, maka akan meningkatkan perencanaan dana pensiun sebesar 1.702 kali. Nilai koefisien regresi future orientation sebesar 0,209 dapat diartikan apabila future orientation mengalami peningkatan 1000 kali, maka akan meningkatkan perencanaan dana pensiun sebesar 209 kali.

$\mathrm{Y}=-3,954+1,702 \mathrm{FL}+0,209 \mathrm{FO}+\mathrm{e}$

\section{Uji Statistik F}

Hasil uji $\mathrm{F}$ menunjukkan besarnya $\mathrm{F}$ hitung adalah 3,557 dengan nilai probabilitas 0,009 . Sehingga dapat diartikan bahwa seluruh variabel independen secara bersama-sama dapat memengaruhi perencanaan dana pensiun. 
Tabel 1

HASIL UJI REGRESI LINIER BERGANDA

\begin{tabular}{lrrrr}
\hline \multicolumn{1}{c}{ Model } & $\begin{array}{c}\text { Unstandardized Coefficients } \\
\text { B }\end{array}$ & Std. Error & \multicolumn{1}{c}{ t } & Sig. \\
\hline (Constant) & $-3,954$ & 6,447 &,- 613 &, 541 \\
FL & 1,702 &, 573 & 2,968 &, 004 \\
FO &, 209 &, 092 & 2,261 &, 026 \\
Usia &,- 349 &, 640 &,- 545 &, 587 \\
Gender &, 747 &, 652 & 1,146 &, 254 \\
\hline Sumber: Output SPSS (data diolah) & & &
\end{tabular}

\section{Uji Statistik t}

Hasil uji statistik $\mathrm{t}$ menghasilkan nilai $\mathrm{t}$ hitung variabel financial literacy sebesar 2,968 dengan nilai signifikansi $0,004<0,05$, nilai $\mathrm{t}$ hitung variabel future orientation sebesar 2,261 dengan nilai signifikansi $0,026<0,05$. Sehingga dapat diartikan kedua variabel tersebut signifikan terhadap perencanaan dana pensiun. Maka artinya terima H1 dan tolak H0. Sedangkan untuk variabel usia dan gender tidak signifikan terhadap perencanaan dana pensiun karena memiliki nilai signifikansi $>0,05$ sehingga terima $\mathrm{H} 0$ dan tolak $\mathrm{H} 1$.

\section{Uji Determinasi}

Tabel 2 menunjukkan nilai Adjusted $R$ Square sebesar 0,086 atau 8,6\%, yang berarti bahwa variabel independen menjelaskan sebanyak $8,6 \%$ terhadap variabel dependen, sedangkan sebanyak $91,4 \%$ dijelaskan oleh variabel independen lain selain yang ada dalam penelitian ini.

Tabel 2

\section{HASIL UJI DETERMINASI}

\begin{tabular}{|c|c|c|c|c|}
\hline Model & $\mathbf{R}$ & R Square & Adjusted R Square & Std. Error of the Estimate \\
\hline 1 & $345^{\mathrm{a}}$ & ,119 & ,086 & 3,288 \\
\hline
\end{tabular}

\section{Pengaruh Financial Literacy terhadap Perencanaan Dana Pensiun}

Financial literacy terbukti berpengaruh signifikan terhadap perencanaan dana pensiun, artinya hipotesis pertama (H1) terdukung. Hal ini searah dengan penelitian Sufian (2016), Klapper \& Panos (2011), Ricci \& Caratelli (2017), Kimiyagahlam et. al. (2019), dan Putri (2013) yang memberikan hasil bahwa ada pengaruh yang signifikan financial literacy terhadap perencanaan dana pensiun.

Hasil ini dipengaruhi oleh beberapa faktor. Responden merupakan PNS, dengan berprofesi sebagai PNS maka responden memiliki pendapatan rutin setiap bulan dan mampu mengelola keuangan pribadi mereka yang berdampak pada perencanaan keuangannya. Selain itu, dengan tingkat pendidikan yang dimiliki oleh PNS dapat disimpulkan bahwa PNS memiliki informasi mengenai pengetahuan keuangan yang lebih baik. Sehingga PNS dapat memanfaatkan informasi mengenai pengetahuan keuangan untuk membuat perencanaan keuangan yang lebih baik.

Tingkat financial literacy yang tinggi pada PNS diharapkan dapat digunakan untuk mengelola keuangan pribadi dan juga menunjang kesiapan terhadap keuangan di masa depan dengan memberikan perhatian kepada perencanaan dana pensiunnya sesuai dengan pengetahuan keuangan yang dimiliki. Karena tingkat financial literacy dapat berpengaruh terhadap pengelolaan keuangan pribadi dan pemahaman seseorang pada perencanaan dana pensiun.

\section{Pengaruh Future Orientation terhadap Perencanaan Dana Pensiun}

Future Orientation terbukti berpengaruh signifikan terhadap perencanaan dana pensiun, artinya hipotesis kedua (H2) terdukung. Hal ini searah dengan penelitian Kimiyagahlam et. al. (2019), 
Kurnia Dwi Sandra \& Achmad Kautsar. Analisis Pengaruh Financial Literacy, Future Orientation, Usia dan Gender terhadap Perencanaan Dana Pensiun PNS di kota Surabaya

Sugihartatik (2019), Mustikarahmawati (2018) dan Kusumawanti (2018) yang memberikan hasil bahwa financial literacy berpengaruh signifikan pada perencanaan dana pensiun.

Hasil ini terjadi dikarenakan berbagai faktor. Responden yang berprofesi sebagai PNS memiliki pendapatan dan mampu menyisihkan dana untuk kesejahteraan di masa pensiun. Hal ini ditunjukkan dengan sebagian besar responden menyatakan setuju pada item pernyataan bahwa responden perlu merencanakan kehidupan setelah masa pensiun mulai dari sekarang, yang dilakukan dengan cara menabung dan berinvestasi untuk menunjang perekonomian saat sudah memasuki masa pensiun.

Responden tentu sudah memikirkan kesejahteraan di masa tuanya, hal ini juga dibuktikan dengan tanggapan responden yang menyatakan setuju bahkan sangat setuju pada item pernyataan bahwa responden ingin memperoleh kehidupan pensiun yang sejahtera. Meskipun, sebanyak $46 \%$ responden menyatakan ragu-ragu terhadap item pernyataan bahwa responden memiliki pengetahuan yang baik mengenai mekanisme pensiun. Akan tetapi, hal ini diimbangi dengan tingginya minat responden untuk mencari informasi mengenai perencanaan dan pengelolaan dana pensiun yang dibuktikan dengan $60 \%$ responden menjawab setuju pada item pernyataan tersebut.

Responden memiliki antusias yang tinggi untuk mencari informasi mengenai perencanaan dan pengelolaan dana pensiun untuk meningkatkan pengetahuannya terkait mekanisme pensiun. Sehingga dapat menunjang perencanaan dana pensiun yang lebih baik guna mendapatkan kehidupan pensiun yang sejahtera.

\section{Pengaruh Usia terhadap Perencanaan Dana Pensiun}

Usia tidak terbukti berpengaruh signifikan terhadap perencanaan dana pensiun, artinya hipotesis ketiga (H3) tidak terdukung. Hal ini tidak searah dengan penelitian Sufian (2016), Moorthy \& Kai (2012) dan Padmajaya \& Juwita (2016) yang memberikan hasil bahwa usia berpengaruh signifikan terhadap perencanaan dana pensiun.

Hasil ini terjadi dikarenakan beberapa faktor. Responden merupakan PNS dengan rentang usia 25-45 tahun dan 46-65 tahun. Dengan persentase 57\% responden merupakan kelompok usia muda dengan usia 25-46 tahun. Responden memiliki pemahaman keuangan yang sangat baik, dan juga memiliki pandangan tentang orientasi masa depan yang cukup baik. Dibuktikan dengan jawaban dan tanggapan responden mengenai pengetahuan keuangan dan orientasi masa depan. Hal ini bertolak belakang dengan penelitian yang dilakukan oleh Sufian (2016) yang menyatakan bahwa seseorang yang dengan usia muda cenderung berpikir bahwa mereka belum saatnya untuk merencanakan terkait pensiun, sedangkan masyarakat dengan usia yang sudah tua memiliki kendala dalam menabung untuk kepentingan perencanaan kehidupan setelah masa pensiun.

\section{Pengaruh Gender terhadap Perencanaan Dana Pensiun}

Gender tidak terbukti berpengaruh signifikan terhadap perencanaan dana pensiun, artinya hipotesis keempat (H4) tidak terdukung. Hal ini tidak searah dengan penelitian Sufian (2016), Kumar et. al. (2019), dan Grace et. al. (2010) yang memberikan hasil bahwa gender berpengaruh signifikan terhadap perencanaan dana pensiun.

Hal ini dapat disebabkan oleh beberapa hal. Responden yang terdiri dari 110 orang PNS, dengan persentase $61 \%$ adalah perempuan. Responden menyatakan bahwa memiliki keinginan untuk tetap bekerja setelah memasuki masa pensiun. Diasumsikan responden baik laki-laki maupun perempuan ingin tetap memperoleh penghasilan meski telah memasuki masa pensiun untuk menunjang keberlangsungan hidup. Karena responden menganggap memiliki kewajiban dan kebutuhan hidup yang sama seperti saat masa bekerja. Hal ini bertolak belakang dengan penelitian yang dilakukan oleh Sufian (2016) yang menyatakan bahwa perempuan cenderung kurang menanggapi informasi terkait perencanaan keuangan dibandingkan laki-laki, yang menyebabkan laki-laki memiliki perencanaan pensiun yang lebih baik. 


\section{KESIMPULAN}

Financial literacy merupakan hal utama yang menjadi faktor paling berpengaruh terhadap perencanaan dana pensiun pada PNS di kota Surabaya. tingkat pengetahuan, pemahaman serta keterampilan dalam mengelola keuangan merupakan hal yang berpengaruh terhadap perencanaan dana pensiun. Selain itu, faktor future orientation atau pandangan tentang masa depan juga berpengaruh. Sedangkan faktor usia dan perbedaan gender tidak berpengaruh terhadap perencanaan dana pensiun pada PNS di kota Surabaya.

Hasil penelitian ini diharapkan dapat digunakan sebagai bahan pertimbangan, pengembangan strategi, maupun pengambilan kebijakan oleh PT. Taspen untuk tidak hanya mengelola dana pensiun dari PNS melainkan juga memberikan sosialisasi pemahaman tentang pentingnya perencanaan dana pensiun. Untuk penelitian selanjutnya disarankan untuk menggunakan variabel pendapatan, money attitude dan self control.

\section{DAFTAR PUSTAKA}

Ajzen, I. (1991). The Theory of Planned Behavior. Organizational Behavior and Human Decision Processes, 50(2), 179-211. https://doi.org/10.1016/0749-5978(91)90020-T

Asokumar, A. (2018). Determinant of Employees ' Retirement Planning: A Review of Malaysian Retirement Plans. Global Business and Management Research: An International Journal, 10(3).

BKN. (2019). Peminat CPNS Naik 12\%, BKN Pastikan Pelaksanaan Seleksi Akuntabel dan Transparan. Retrieved March 21, 2020, from www.bkn.go.id website: https://www.bkn.go.id/berita/peminat-cpns-naik-12-bkn-pastikan-pelaksanaan-seleksiakuntabel-dan-transparan

BKN. (2019). Statistik PNS per Desember 2018: Tenaga Guru dan Kesehatan Menjadi Fokus Pemenuhan Kebutuhan ASN. Retrieved March 3, 2020, from www.bkn.go.id website: https:/www.bkn.go.id/wp-content/uploads/2019/04/Statistik-PNS-per-Desember-2018-TenagaGuru-dan-Kesehatan-Menjadi-Fokus-Pemenuhan-Kebutuhan-ASN.pdf

BPS. (2014). Proyeksi Penduduk menurut Provinsi, 2010-2035. Retrieved March 4, 2020, from www.bps.go.id website: https://www.bps.go.id/statictable/2014/02/18/1274/proyeksi-pendudukmenurut-provinsi-2010---2035.html

BPS. (2017). Statistik Penduduk Lanjut Usia 2017. Retrieved March 4, 2020, from www.bps.go.id website: https://www.bps.go.id/publication/2018/04/13/7a130a22aa29cc8219c5d153/statistikpenduduk-lanjut-usia-2017.html

Chen, H., \& P.Volpe, R. (1998). An Analysis of Personal Financial Literacy Among College Students. Zhongguo Jiguang/Chinese Journal of Lasers, 7(2), 107-128. https://doi.org/10.3788/CJL201643.0811001

Chinen, K., \& Endo, H. (2012). Effects of Attitude and Background on Personal Financial Ability: A Student Survey in the United States. International Journal of Management, 29(1), 33.

CNN Indonsia. (2018). Hanya 3,1 Persen Penduduk Produktif di RI yang Wirausaha. Retrieved March 21, 2020, from www.cnnindonesia.com website: https://www.cnnindonesia.com/ekonomi/20181018210657-92-339664/hanya-31-persenpenduduk-produktif-di-ri-yang-wirausaha

Ghozali, I. (2016). Aplikasi Analisis Multivariate Dengan Program IBM dan SPSS 23 (8th ed.). Badan 
Kurnia Dwi Sandra \& Achmad Kautsar. Analisis Pengaruh Financial Literacy, Future Orientation, Usia dan Gender terhadap Perencanaan Dana Pensiun PNS di kota Surabaya

Penerbit Universitas Diponegoro.

Grace, D., Weaven, S., \& Ross, M. (2010). Consumer retirement planning: An exploratory study of gender differences. Qualitative Market Research, 13(2), 174-188. https://doi.org/10.1108/13522751011032601

Kim, K. T., Hanna, S. D., \& Chen, S. C. (2014). Consideration of retirement income stages in planning for retirement. Journal of Personal Finance, 13(1), 52.

Kimiyagahlam, F., Safari, M., \& Mansori, S. (2019). Influential Behavioral Factors on Retirement Planning Behavior: The Case of Malaysia. Journal of Financial Counseling and Planning, 30(2), 244-261. https://doi.org/10.1891/1052-3073.30.2.244

Klapper, L., \& Panos, G. A. (2011). Financial literacy and retirement planning: The Russian case. Journal of Pension Economics and Finance, 10(4), 599-618. https://doi.org/10.1017/S1474747211000503

Kumar, S., Tomar, S., \& Verma, D. (2019). Women's financial planning for retirement: Systematic literature review and future research agenda. International Journal of Bank Marketing, 37(1), 120-141. https://doi.org/10.1108/IJBM-08-2017-0165

Kusumawanti, D. (2018). Pengaruh Materialisme, Orientasi Masa Depan dan Pendapatan Terhadap Perencanaan Dana Pensiun di Surabaya. Thesis STIE Perbanas, 1-13. Retrieved from http://eprints.perbanas.ac.id/id/eprint/4008

Menpan. (2016). Hingga 2020, Sebanyak 752.271 PNS akan Pensiun. Retrieved March 4, 2020, from www.menpan.go.id website: https://www.menpan.go.id/site/berita-terkini/hingga-2020sebanyak-752-271-pns-akan-pensiun

Mischel, W., Shoda, Y., \& Rodriguez, M. L. (1989). Delay of gratification in children. Science, 244(4907), 933-938. https://doi.org/10.1126/science.2658056

Moorthy, M. K., \& Kai, N. Z. (2012). A Study on the Retirement Planning Behaviour of Working Individuals in Malaysia. International Journal of Academic Research in Economics and Management Science, 1(2).

Mustikarahmawati, D. (2018). Pengaruh Orientasi Masa Depan, Money Attitude dan Self Control pada Perencanaan Dana Pensiun di Surabaya. Thesis STIE Perbanas, 1-14. Retrieved from http://eprints.perbanas.ac.id/id/eprint/4060

Padmajaya, D., \& Juwita, R. (2016). Analisis Pengaruh Faktor-Faktor Literasi Keuangan terhadap Perencanaan Keuangan untuk Menghadapi Masa Pensiun Guru ( Studi Kasus SMK Negeri 1 Kota Palembang ). Thesis STIE Multi Data Palembang, 1-13. Retrieved from http://eprints.mdp.ac.id/2073/1/Jurnal-2013200047.pdf

PT.Taspen. (2018). Program Pensiun. Retrieved March 4, 2020, from www.taspen.co.id website: https://www.taspen.co.id/\#/layanan/pensiun?_k=b2um1s

Putri, D. (2018). Pengaruh Literasi Keuangan, Sikap Pengelolaan Keuangan Keluarga dan Pengalaman Keuangan terhadap Perencanaan Pensiun Kelarga di Kabupaten Tuban. Thesis STIE Perbanas, 1-13. Retrieved from http://eprints.perbanas.ac.id/id/eprint/3587

Rahman, E. (2018). Pengaruh Orientasi Masa Depan Dan Sikap Keuangan Terhadap Perilaku Perencanaan Dana Pensiun Dengan Pengetahuan Keuangan Sebagai Variabel Moderasi. Thesis STIE Perbanas, 1-13. Retrieved from http://eprints.perbanas.ac.id/id/eprint/3546 
Ricci, O., \& Caratelli, M. (2017). Financial literacy, trust and retirement planning. Journal of Pension Economics and Finance, 16(1), 43-64. https://doi.org/10.1017/S1474747215000177

Shafee, N. B. (2018). Future Retirement Planning Among Malacca Youth. Global Business and Management Research: An International Journal, 10(3), 372-381.

Sufian, M. (2016). The Factors Influencing Retirement Planning Management (RPM) Among Sime Darby Research Employees: A Conceptual Framework. Journal of Business Innovation, 1(1), $1-14$.

Sugihartatik, F. I. (2019). Hubungan orientasi masa depan, pengetahuan keuangan dan kecerdasan spiritual dengan perilaku perencanaan dana pensiun keluarga. Journal of Business \& Banking, 7(1), 17-30. https://doi.org/10.14414/jbb.v7i1.966

Wardani, A., \& Silvy, M. (2018). Pengaruh Pengetahuan Keuangan dan Pendapatan Terhadap Perilaku Perencanaan Dana Pensiun Dengan Locus of Control Sebagai Variabel Mediasi. Accounting Analysis Journal, 4(672013167), 0-18. 